\title{
(Epi) Genetics and the complexity of diabetes mellitus
}

\author{
Maria Lúcia Corrêa-Giannella
}

'Laboratório de Carboidrato e Radioimunoensaio (LIM-18), Hospital das Clinicas, Faculdade de Medicina, Universidade de Sao Paulo (HCFMUSP), Sao Paulo, SP, Brasil. Programa de Pós-Graduação em Medicina, Universidade Nove de Julho, Sao Paulo, SP, Brasil

Correspondence to:

Maria Lúcia Corrêa-Giannella1 maria.giannella@fm.usp.br

Received on Feb/19/2018 Accepted on Feb/20/2018 DOI: $10.20945 / 2359-3997000000002$
B oth type 1 (T1D) and type 2 (T2D) diabetes mellitus are complex diseases to which environmental and genetic factors contribute (1). Recently, epigenetic factors have also been recognized as important not only in the etiopathogenesis of these conditions, but also in the development of their chronic complications (2). As if the interaction among environment, genetics and epigenetics is not complex enough, each of these factors has their own complexity. For instance, regarding the genetic setting, both T1D and T2D are polygenic diseases for which several susceptibility genes contribute, each with a relatively small participation (1). In addition, susceptibility genes may vary among different populations, reason why genetic studies should be reproduced in the population of interest.

In this issue of Archives of Endocrinology and Metabolism (AE\&M), two manuscripts address, respectively, genetic and epigenetic factors associated with diabetes. Pirozzi and cols. (3) evaluated in a population of Brazilian obese patients from the Southeast region, the association of T2D with two polymorphisms, rs1799752 in the gene encoding angiotensin I converting enzyme $(A C E)$ and rs1801133 in the gene encoding methylenetetrahydrofolate reductase $(M T H R F)$. MTHRF is the enzyme that catalyzes the conversion of 5,10-methylenetetrahydrofolate to 5-methyltetrahydrofolate whose deficiency increases plasmatic homocysteine concentrations. Both polymorphisms had been previously studied for the association to T2D with conflicting results in different ethnic groups $(4,5)$. No association of these polymorphisms with T2D was found by Pirozzi and cols., in agreement with a previous study performed in Brazilian patients from the South region, which also did not find association of T2D with rs1799752 in the $A C E$ gene (6). Given the admixture which characterizes the Brazilian population and the distinct genetic background even among the different Brazilian regions (7), it is important that such genetic studies are carried out, preferably in larger series of patients.

Micro RNAs (miRNAs) are one of the epigenetic mechanisms; they are small non-coding RNAs that repress gene expression at the post transcriptional level (8) and because they regulate several cellular processes, they have been implicated in human diseases (9). miRNA expression profiles have been explored as a potential tool to classify disease states and, in certain situations, to diagnostic applications (10). In the second manuscript, García-Días and cols. evaluated the expression of three miRNAs in peripheral blood mononuclear cells (PBMC) from TID patients as compared to control (non-diabetes) subjects. A higher expression of miR-155 and a lower expression of miR-326 and miR-146a were observed in TID patients in comparison to non-diabetes subjects. Interestingly, miR-155 expression was associated with autoimmunity and with the inflammatory status (11). It had been previously demonstrated that different inflammatory mediators, such as tumor necrosis factor 
(TNF), are able to induce miR-155 expression in macrophages (12). Because hyperglycemia increases the production of TNF and other cytokines, it is possible that increased miR-155 expression in PBMC from TID patients reflects a sustained inflammatory state associated with the suboptimal metabolic control (11). Studies like this one exploring the association between clinical and biochemical variables and aberrant expression of miRNAs can improve the understanding of the epigenetic mechanisms triggered by longstanding hyperglycemia, which underlie the concept of Metabolic memory.

Disclosure: no potential conflict of interest relevant to this article was reported.

\section{REFERENCES}

1. Permutt MA, Wasson J, Cox N. Genetic epidemiology of diabetes. J Clin Invest. 2005;115(6):1431-9.

2. Block T, El-Osta A. Epigenetic programming, early life nutrition and the risk of metabolic disease. Atherosclerosis. 2017;266:31-40.

3. Pirozzi FF, Belini-Junior E, Okumura JV, Salvarani M, BoniniDomingos CR, Ruiz MA. The relationship between of ACE I/D and the MTHFR C677T polymorphisms in the pathophysiology of type 2 diabetes mellitus in a population of Brazilian obese patients. Arch Endocrinol Metab. 2018;62(1):21-6.
4. Abbas S, Raza ST, Ahmed F, Ahmad A, Rizvi S, Mahdi F. Association of genetic polymorphism of PPARy-2, ACE, MTHFR, FABP-2 and FTO genes in risk prediction of type 2 diabetes mellitus. J Biomed Sci. 2013 Oct 25;20:80.

5. Yako YY, Guewo-Fokeng M, Balti EV, Bouatia-Naji N, Matsha TE, Sobngwi $\mathrm{E}$, et al. Genetic risk of type 2 diabetes in populations of the African continent: A systematic review and meta-analyses. Diabetes Res Clin Pract. 2016;114:136-50.

6. Wollinger LM, Dal Bosco SM, Rempe C, Almeida SE, Berlese DB, Castoldi RP, et al. Role of ACE and AGT gene polymorphisms in genetic susceptibility to diabetes mellitus type 2 in a Brazilian sample. Genet Mol Res. 2015;14(4):19110-6.

7. Torres AJ, Angelo AL, Netto EM, Sampaio GP, Souza DF, Inocêncio $L A$, et al. Reference range forT lymphocytes populations in blood donors from two different regions in Brazil. Braz J Infect Dis. 2009;13(3):221-5.

8. Bartel DP. MicroRNAs: genomics, biogenesis, mechanism, and function. Cell. 2004;116(2):281-97.

9. Miska EA. How microRNAs control cell division, differentiation and death. Curr Opin Genet Dev. 2005;15(5):563-8.

10. Blondal T, Jensby Nielsen S, Baker A, Andreasen D, Mouritzen $P$, Wrang Teilum M, et al. Assessing sample and miRNA profile quality in serum and plasma or other biofluids. Methods. 2013;59(1):S1-6.

11. García-Días DF, Pizarro C, Camacho-Guillén P, Codner E, Soto N, Pérez-Bravo F. Expression of miR-155, miR-146a, and miR-326 in T1D patients from Chile: relationship with autoimmunity and inflammatory markers. Arch Endocrinol Metab. 2018;62(1):27-33.

12. O'Connell RM, Taganov KD, Boldin MP, Cheng G, Baltimore D. MicroRNA-155 is induced during the macrophage inflammatory response. Proc Natl Acad Sci U S A. 2007;104(5):1604-9. 